\title{
COMICS AND COLLECTIVE AUTHORSHIP
}

\author{
CHRISTY MAG UIDHIR
}

\begin{abstract}
"I've always been more interested in what's possible in the future than what's happened in the past. I've never been very nostalgic and have never been much of a collector. You're never going to hear me moaning about how much better comics were when I was a kid, because they weren't! Comics are much better now...There are more diverse genres, more diverse creators, more genderbalanced (not as much as they should be, but we're on our way), they're more substantial in terms of literate content, they are more adventurous in terms of design, there's more virtuosity in a variety of styles, there's more exchange of ideas across national boundaries, there's more personal work being promoted, there's increased public perception for a variety of comics for a variety of different applications. Comics are being used for more things, read by more people, and have more of an essential importance to the culture, relevance to the culture, and effect on the culture than they ever have." -Scott McCloud, from an interview with Christopher Irving (2010).
\end{abstract}

\section{INTRODUCTION}

Most mass-art comics (e.g., "superhero" comics) are collectively produced, i.e., different people are responsible for different production elements. Although this collectivity largely defines the history of mass-art comic production throughout, the nature of that collectivity has shifted from the discrete, assembly-line model of the Golden Age to the comparatively more nuanced and inclusive contemporary model of the Modern Age. Moreover, this shift appears reflected in (or at least is in step with) the changing interests of comic readership. That is, while content (stories, pictures, characters) remains the primary object of interest, readers have also developed production-oriented interests both broad and narrow, ranging from loyalty to certain titles (e.g., The Spectacular Spider-man, Detective Comics) or publishers (e.g., Dark Horse Comics, Top Shelf Productions) to devotion to (or rancor for) certain writers (e.g., Alan Moore, Pat Mills), line artists (e.g., Rags Morales, Lee Bermejo), inkers (e.g., Joe Sinnott, George Roussos), colorists (e.g., Laura Martin, Lynn Varley), or team-ups (e.g., Jeph Loeb \& Tim Sale, Grant Morrison \& Frank Quitely). Of course, comic readers, regardless of Age, recognize and value wellconstructed narratives, well-written scripts, and well-drawn panels. What appears to set contemporary comic readership apart from its predecessors, however, is a shift in the value of, preferences for, expectations about, and attention paid towards the purely visual elements of 
comics, ${ }^{1}$ helping to spark a largely heretofore absent visual, if not art historical, interest in comics from previous eras and the figures involved in their production (many of whom were largely ignored during their own lifetime). ${ }^{2}$

As consumers of comic books see themselves less as "readers" and more as "viewers", so too do they see visual elements of comics as being on a level with non-visual elements not just in terms of stylistic variety (and the complexities and subtleties therein) but, more importantly, in terms of contributory significance such that illustrators can be just as important as writers (if not more so). Adding to this, technological innovations in certain production processes have created an environment in which the contributions of colorists, inkers, and even letterers can become just as significant as those of writers and line artists (e.g., Dave Stewart's coloring in The Umbrella Academy, John Severin's inking run on Sgt. Fury and his Howling Commandos, and Todd Klein's work as letterer in Sandman). As a result, production roles previously thought merely workman-like are now regarded in some cases as being (or as having all along been) significantly or even uniquely contributory (e.g., since the early 90s, Best Colorist, Best Inker, and Best Letterer have been included as principal categories of industry achievement by both the Eisner Awards and the Harvey Awards). As the comic medium comes into its own, not only does authorship of a comic become all the more difficult to determine but the issue of comic authorship itself becomes all the more pressing.

Here's the problem. Common sense tells us that comics (comic books, comic strips, graphic novels, etc.) are the sorts of things that have authors. Commonsense intuitions about authorship, however, are largely (if not exhaustively) informed by cases involving standardly individually-produced works, specifically the standard sorts of works in the literary and visual arts (e.g., novels, poems, paintings, sculpture). Comics, however, at least of the sort under discussion, are standardly collectively-produced. So, the mere fact that commonsense intuitions may reliably track authorship for standard literary works doesn't mean that we should expect them to likewise reliably track authorship for comics. ${ }^{3}$ Moreover, common sense quickly abandons us in cases involving numerous agents collectively engaging in highly complex production processes, of which the standard mass-market comic is just such a case. Given this, one might understandably be tempted to inform comic authorship by looking to other media with

\footnotetext{
${ }^{1}$ Of course, the fact that contemporary comics may be visually more sophisticated than comics were half a century ago doesn't mean that contemporary comics are thereby better (either visually or simpliciter) than their Golden Age brethren.

${ }^{2}$ The increased attention to, study of, and value placed upon comics from earlier Ages largely concerns their purely visual elements, often having little to do with (or even in spite of) their narrative content (e.g., we value classic Graham Ingels Tales from the Crypt comics and Burne Hogarth Tarzan Sunday strips not for narratives but for their visuals).

${ }^{3}$ At least to the extent we take the medium of comics itself to be outside literature (either as a fully stand alone medium or as a hybrid medium related to but distinct from other literary media). For a discussion of this, see (Meskin 2009).
} 
similarly collective and complex production processes (e.g., cinema) and the models of authorship at play therein (e.g., auteur theory-the director as principal, if not sole, cinematic author). ${ }^{4}$

The problem is that intuitions about authorship are themselves informed by intuitions or implicit background assumptions about production and its principal constitution-to import the former from other media is also to import the latter. For instance, auteur theory construes authorship as being largely a matter of a singular individual exerting sufficiently substantial control over production of a work such that the work is seen as executing that individual's singular vision, being in that individual's singular style, employing that individual's singular technique (e.g., Robert Bresson, Alfred Hitchcock, Akira Kurosawa, Stanley Kubrick, Orson Welles are all auteurs of cinema). To be sure, importing auteur theory (or some translation thereof) from cinema may well capture authorship in analogously auteur cases in comics (e.g., Jack Kirby, Carl Barks, Harvey Kurtzman, Daniel Clowes, Chris Ware). However, assuming auteur theory to provide a standard let alone exhaustive account for comic authorship requires endorsing a demonstrably false view of comic production, namely one predicated substantively if not entirely on a single individual (the putative auteur) exclusively occupying or substantially controlling any and all production roles potentially relevant to ascriptions of comic authorship (writer, inker, penciller, colorist, letterer, editor, etc.). ${ }^{5}$ Of course, this all assumes that the auteur theory provides productive and coherent account of cinematic authorship-a view for which currently almost no philosopher would argue let alone readily assume to be the case. As such, the appeal to auteur theory seems capable of nothing more than translating what is a bankrupt theory of cinematic authorship into an equally bankrupt theory of comic authorship. ${ }^{6}$

I take the lesson here to be that if we are to take the comic seriously as a medium, then we shouldn't be looking to other media either implicitly or explicitly to inform comic authorshipwhat it is to author a comic should have everything to do with what it is to be a comic. Given the collective-production of comics, the more disparate comic production roles we begin to regard as significantly or uniquely contributory, the more difficult questions of comic authorship become, and the more we view various distinct production roles as potentially constitutive is the more we must view comic authorship as potentially collective authorship. Given the general unreliability of intuitions with respect to collective authorship (coupled with our general unfamiliarity with the medium), we must look to find a principle of comic authorship out of

\footnotetext{
${ }^{4}$ Though perhaps in terms of production, a more apt comparison for comics would be serial works for television. For the most famous example of the origins, defense, and employ of cinematic auteur theory, see Andrew Sarris' highly influential book The American Cinema: Directors and Directions 1929-1968, first published in 1968.

${ }^{5}$ For a discussion of auteur theory in comics, see (Ault 2004).

${ }^{6}$ With respect to authorship concerns, the medium of cinema is certainly no better, and likely much worse, off than that of comics.
} 
which authorship questions can be settled for comics simpliciter. Furthermore, any such principle found must also be capable of grounding a principled distinction between collective production and collective authorship; should this distinction be absent, any proper manner of framing the central descriptive and evaluative questions for comics must likewise be absent. Quite obviously we need a theory of comic authorship. No doubt less obvious is how we should proceed and exactly what such a theory should look like.

\section{A Cautious Set-Up}

Given that philosophical analysis of comics is rather recent a development, at least when compared to that of other media, the philosophy of comics looks impoverished and its terrain appears little mapped. Accordingly, we should take care not to make any unnecessary claims, entail any unnecessary commitments, or form any unnecessary allegiances. To this end, I propose the following initial (prima facie) constraints on theory of comic authorship.

1) Comics needn't have authors but comics must be the kinds of things that can have authors.

For instance, if an account of comic authorship entails that if $w$ has no author then $w$ is not a comic, then that account of comic authorship selects for theory of comics of a certain sort and not others-this is precisely the sort of unnecessary commitment we at least initially ought to be avoiding. Given the background assumption that comics are the sorts of things that can have authors, we should take the relationship between theory of authorship and theory of comics to entail only the following:

2) Any responsible theory of authorship must be able to account for comics being the kinds of things that can have authors.

3) Any theory of comics must predicate comic authorship on a responsible theory of authorship.

This ensures both that authored comics must be no different qua comic than unauthored comics and also that comic authors must be no different qua author than authors of non-comics (e.g., poems, novels, paintings, songs, etc.). Any theory of authorship unable to account for comics being the sorts of things that can have authors should come off as exceedingly strange and strike one as being motivated by concerns well outside the domain of authorship as standardly conceived; so too for any theory of comics entailing that comics cannot be the sorts of things that have authors as standardly conceived. Accordingly, merely to claim in philosophical earnest that [comics cannot have authors] requires employing either a radically revisionary notion of comic or a wildly irresponsible notion of authorship.

4) Comic authorship itself should not depend on the endorsement of (or the allegiance to) any particular definition of comics. 
The mere fact that theory of comics $T_{1}$ (comic iff $\Theta$ ) competes with theory of comics $T_{2}$ (comic iff $\Phi)$ should itself entail only that the corresponding accounts of comic authorship differ in specification, and not a difference in comic authorship itself (i.e., its minimal structure). That is, where $\mathbf{R}$ is the minimally specified relation holding between an author of a thing and that thing so authored, it should be the case that an agent standing in (minimally specified) relation $\mathbf{R}$ to $\Theta$ is an author of a comic (according to $T_{1}$ ) if and only if an agent standing in relation $\mathbf{R}$ to $\Phi$ is an author of a comic (according to $T_{2}$ ). Failure for this to be the case entails that either according to $T_{1}$ or according to $T_{2}$, a comic is not the kind of thing that can have an author.

5) Comic conventions and practices are in the main (more or less) responsible and coherent but needn't be regarded as absolute.

For instance, if comic convention and practice suggests that the inker, colorist, letterer, and breakdown artist are candidates for authorship, then any theory of comic authorship ought to allow for that (but needn't entail that).

Of course, one might object that this is too cautious, i.e., no account of comic authorship could plausibly satisfy the above constraints while also remaining a well-specified and robust account. I agree entirely; in fact, as I soon show, that's entirely the point. Having to sketch and defend any well-specified, robust theory of comic authorship ought to first require having to sketch and defend a well-specified, robust theory of comics. As to the robust, well-specified nature of being a comic, I simply haven't a clue; however, I do have an idea about what it is to be an author. ${ }^{7}$ Instead of offering a theory of comic authorship, my goal here is to provide the framework for determining comic authorship, i.e., to provide a responsible theory of authorship that when taken in concert with a theory of comics says exactly what it is to author a comic (collectively or otherwise). Moreover, I take my theory of authorship to act as a constraint for a theory of comics. That is, should any theory of comics, when taken with my theory of authorship, yield an incoherent account of comic authorship, then that theory of comics is itself incoherent or itself entails that comics cannot even in principle be authored (collectively or otherwise), such that, any (non-empirical) difficulties had by a theory of comics with respect to comic authorship are simply difficulties had by that theory of comics with respect to comic.

\section{Minimal AutHORSHIP (OF SORTS)}

According to most theories of authorship, what it is to be an author is to stand in such-and-such relation to a work; furthermore, all authors stand in the same relation to the works they author regardless of the varieties of disparate media descriptions under which those works may appear

\footnotetext{
${ }^{7}$ My view of authorship is fully fleshed out and explained in depth in (Mag Uidhir 2011).
} 
(e.g., poems, novels, paintings, sculptures, films, comics). On this view, what it is to be the author of a work of one sort (e.g., a poem) is just what it is to be the author of a work of any other sort (e.g., a comic)—what it is to be the author of a work is independent of what it is for a work to be a certain sort (e.g., poem, painting, film, or comic). This of course ignores the very real and very substantial differences in the nature of production of works under those various descriptions. The result of this is a tendency to force-fit challenging sorts of works (i.e., those involving highly complex and collective production processes) into models of a standard, more familiar sort (i.e., those typically involving a single agent carrying out or fully controlling all relevant aspects of production). The more unfamiliar and challenging the medium, the more attributing authorship to works under that description requires doing violence to that medium; the more complexly collective the production, the more distinctions between collective production and collective authorship reduce to games of blind intuition.

I provide an alternative to the above view, but in doing so I do not claim merely that a work being of a certain sort or under a certain description matters for what it is to be an author of that work. Rather, I claim that authorship itself must be work-description relative, i.e., we must abandon the two-place relation $x A w$-authorship-of-a-work-in favor of the three-place relation $x A(F w)$-authorship-of-a-work-as-an- $F$ (where $F$ is some work-description). Only authorship as a three-place relation between agents, works, and work-descriptions can underpin crucial and productive distinctions between singularly-authored collectively-produced works and collectively-authored collectively-produced works.

On my view, authorship-of-a-work-as-an-F minimally entails the following for an agent $(A)$, a work $(w)$, and a work-description $(F)$ :

$A$ is an author of $w$ as an $F$ if and only if $A$ is directly responsible, at least in part, for $w$ as an $F$.

To be an author of a work under a description is to be directly responsible, at least in part, for that work being under that description, i.e., to be directly responsible for the way in which that work satisfies the conditions for being under that description (e.g., to be an author of a work as a poem is to be directly responsible for the way in which that work satisfies the conditions for being a poem). To help illustrate this, assume for the sake of argument and simplicity the following. Let $C$ be the set of all and only those features essential for work-description $F$. So,

Work $w$ is an $F$ if and only if $w$ possesses the features in $C$.

From this, the following:

$A$ is the author of $w$ as an $F$ if and only if $A$ is directly responsible, at least in part, for $w^{\prime} s$ possession of the features in $C$.

Further specified with the following: 
For $A$ to be directly responsible, at least in part, for $w^{\prime}$ s possession of the features in $C$ is for $A^{\prime}$ s intentions to figure substantively in $w^{\prime}$ s possession of at least one of the features in $C .8$

For instance, if $w$ is a poem, then if $A$ is the author of $w$ as a poem, then $A^{\prime}$ s intentions must substantively figure in that work being a poem (the way in which that work satisfies the conditions for being a poem). For $w$ to be the particular poem that it is, is for $w$ to be a poem in a particular sort of way (to satisfy the conditions for being a poem in virtue of the particular features it possesses). Authorless poems, if there can be such things, then are works that satisfy the conditions for being a poem but works for which no one is directly responsible, at least in part, for the particular way in which the work satisfies those conditions. If $A$ is an author of $w$ as a poem, then it cannot be the case that $A$ is directly responsible for $w$ being a poem but not directly responsible for the particular way in which $w$ is a poem. So, being the author of $w$ as a poem entails being the author of that particular poem.

Additionally, I take there to be two broad classes of authorship: singular and collective (assume $\mathrm{A} \neq \mathrm{B}$ ).

Singular Authorship: Only $A$ is an author of $w$ as an $F$.

A subspecies of which is:

Conjunctive Authorship: Only $[A$ and $B \ldots]$ is an author of $w$ as an $F$, but neither $A$ nor $B \ldots$ taken alone is an author of $w$ as an $F .^{9}$

The other broad, distinct class is:

Collective Authorship: $A$ and $B \ldots$ are authors of $w$ as an $F$.

Prima facie, collective authorship entails collective production-to be collectively produced just is to be the product of activities with multiple, distinct intentional sources. For my purposes, I do not count as collectively produced works produced by a single intentional source where that source is some group or collective agent (collective intentions). Collective production, however, should neither entail nor suggest collective authorship.

For instance, most mass-market films are collectively produced, but while I suppose that key grips fulfill crucial production roles, key grips are not thereby authors of films. Likewise, many prints are collectively produced, and while I suppose that print technicians and master

${ }^{8}$ I use the term 'substantively' to mean at least non-trivially and non-accidentally and at most exhaustively or essentially.

${ }^{9}$ For example, consider the painting United States: Most Wanted (1994). There are seemingly only two candidates for authorship of the painting, Vitaly Komar and Alex Melamid. Both Komar and Melamid claim, however, that neither authors the painting; instead, they claim that there is but one author of Most Wanted, which is [Komar \& Melamid], the artist team made up of Vitaly Komar and Alex Melamid - the team, not its members taken alone, is the source of the substantively figuring intentions. I want to allow at least in principle for such claims to be true. 
printmakers play critical production roles for prints, they are not (at least not obviously) thereby authors of the prints they help produce. We don't discount key grips and print technicians as authors because they don't fill significant production roles - they obviously do. Rather, we regard the activities in which key grips and print technicians engage, though they be however complex and highly skilled, as being (at least in standard cases) broadly directed by —or facilitating those activities directed by - the intentions of others (e.g., film directors, cinematographers, graphic designers, print artists). Of course, while collective production doesn't entail collective authorship, many collectively produced works under certain workdescriptions are collectively authored. The operative question then to which we can now turn is whether comic is just such a work description.

\section{Minimal Authorship (OF THE COMIC SORT)}

Assume comic to be an author-relevant work-description. From this, we get the following:

A work $w$ is a comic if and only if $w$ possesses the features in $C$ where $C$ is the set of all and only those features essential for being a comic.

And from this:

Someone is the author of $w$ as a comic if and only if that someone is directly responsible, at least in part, for $w^{\prime}$ s possession of the features in $C$.

Further specified by the following:

For someone to be directly responsible, at least in part, for $w^{\prime}$ s possession of the features in $C$ is for the intentions of that someone to substantively figure in $w^{\prime}$ s possession of at least one of the features in $C$.

Note I am not assuming that any theory of comics must be an essentialist account; I merely employ one for the sake of simplicity. ${ }^{10} \mathrm{My}$ view should perform equally well for more pluralist or open-ended accounts. ${ }^{11}$ I claim only that for a thing that is a comic, someone is an author of that comic just in case that someone is directly responsible at least in part for whatever makes that thing a comic, and this itself doesn't require that what makes that thing a comic must be the same as what makes another thing a comic (or make any other thing a comic). Of course, theories of comics with nebulous or variable satisfaction conditions for being a comic unsurprisingly ought to result in equally nebulous or variable satisfaction conditions for being an author of a comic.

${ }^{10}$ For an essentialist definition of comics, see (Hyman \& Pratt 2005). For a response to essentialist definitions of comics, see (Meskin 2007).

${ }^{11}$ E.g., theories involving some open-ended and ever-expanding set of relevant features $\left\{f_{1}, f_{2}, \ldots\right\}$ such that for a work to be a comic just is for that work to have some combination of those features with no particular combination itself being necessary. 
Also note that I do not target trivially essential/necessary features, e.g., being an object, being a non-minotaur, being [a comic or a marmoset]. Likewise trivial and so excluded from $C$ are redundant or non-constitutive essential/necessary features, i.e., a feature for which $w$ satisfying the conditions for being an $F$ (necessarily) entails $w$ possessing that feature, but possessing that feature is not itself constitutive of being an $F$, i.e., not itself a distinct condition that $w$ must satisfy in order to be an F. For instance, I consider being an artifact to be a nonconstitutively (and so trivially) essential feature for being a chair; however, while a thing satisfying the conditions for being a chair (necessarily) entails the thing being an artifact, being an artifact is not itself constitutive of the thing being a chair, i.e., a distinct condition a thing must satisfy in order to be a chair. For example, suppose a thing to be a chair just in case that thing i) is made with the purpose of being sat upon and ii) is able to be sat upon as the result of being successfully so made. Clearly, the extra condition [iii) is an artifact] adds nothing of any substance-anything satisfying i) and ii) ipso facto satisfies iii). Accordingly, the assumption that comics must be artifacts need entail only that any $w$ possessing all features in $C$ must thereby be an artifact; it needn't (and I assume doesn't and shouldn't) entail that being an artifact is itself constitutive of being a comic, i.e., itself a distinct feature in $C$. As such, we shouldn't expect someone to be an author of a comic merely in virtue of being directly responsible for its bare artifactuality and nothing else (e.g., writer, line artist, letterer, artifactualist). ${ }^{12}$

Finally, note that this allows both for the possibility of authorless comics and for the possibility of conjunctive but single authorship. That is, it allows there to be no such single person who satisfies the conditions of authorship. This is consistent both with the view that comics needn't have authors and the view that comics can have only singular authorship (i.e., the author must be either a single person or a conjunction of persons such that no conjunct taken by itself is an author and only the conjunction is itself sufficient). ${ }^{13}$ Of course, this makes an account of comic authorship only as good as the account of comics upon which it is based, but this is what we ought to expect.

\section{SOME WORK FOR A THEORY OF COMIC AUTHORSHIP}

Motivating interest in comic authorship and its corollaries (especially the method of its determination) ought to be relatively straightforward; clearly authorship matters for a variety of

\footnotetext{
${ }^{12}$ For example, suppose that a comic must be a print. While the printer may be directly responsible for a comic being a print (simpliciter), this doesn't entail that the printer is thereby directly responsible for the comic being the particular print that it is. While the former may warrant production credit, only the latter warrants ascription of authorship. In what follows, I discuss such distinctions in terms of production being either commissioned or appropriated. For a detailed discussion of this, see (Mag Uidhir 2011).

${ }^{13}$ It should also appeal both to those in favor of actual intentionalism and to those opposed to it (e.g., perhaps intentions need only be rationally reconstructed instead of psychologically real, or perhaps authors are constructs rather than actual agents).
} 
reasons (e.g., legal, moral, social, artistic) germane for a host of concerns (e.g., ownership, authenticity, interpretation, aesthetic value). Additionally, some philosophers claim authorship to play a foundational if not also essential metaphysical role for works (of a certain sort), especially with respect to work identity and work individuation (e.g., if a work has an author, could it have had a different author (or no author) and still be that work, are two works identical in all respects save authorship the same work or are they nevertheless different works, and is it even possible for a work to be identical in all respects save authorship). ${ }^{14}$

To help illustrate this, consider Batman: The Killing Joke. Most consider this widely influential comic to be (at least in a pretheoretic sense) collectively authored by Alan Moore, the writer, and Brian Bolland, the line artist. In addition to the line art, Brian Bolland had intended to also do the coloring for the comic's 1988 release, but due to time constraints, John Higgins was employed instead as the colorist. For the 2008 "re-release" of The Killing Joke, Bolland made good on his decades-old intentions by re-coloring the entire comic, the result of which was a coloring substantially different from that had by The Killing Joke released in 1988. For instance, 1988 release featured the iconic Batman chest emblem-yellow oval surrounding the bat symbol-while the 2008 release removed both the oval and the yellow. In the 1988 release, the flashback scenes (the Joker's pre-Joker past) were fully colored; in the 2008 release, however, those scenes were entirely colored in sepia tones save things traditionally considered or implied to be red were actually colored red (e.g., cooked crawfish, Red Hood's hood and cape). Further still, the 1988 release looks like a comic from the 1980s largely because of its coloring; likewise, and perhaps problematically, the coloring in the 2008 release reflects its time-it looks like a comic from 2008. Given all this, it seems legitimate to ask whether Batman: The Killing Joke (1988) is the same comic as Batman: The Killing Joke (2008). ${ }^{15}$

One way to answer the above is to assume that authorship matters for work identity. If colorists ought to be counted as authors (at least in these specific cases), then John Higgins is an author of The Killing Joke (1988) but not of The Killing Joke (2008). If authorship must be preserved, then The Killing Joke (1988) is not the same comic as The Killing Joke (2008), and this would hold even were they otherwise qualitatively identical. Of course, to employ this individuation method requires support from theory of comics according to which colorists can count as authors. If knowing the specific conditions under which a colorist counts as an author of a comic entails knowing the specific conditions under which something counts as a comic, then so too must knowing the specific conditions under which something counts as that comic.

\footnotetext{
${ }^{14}$ For examples, see (Levinson 1990; Rohrbaugh 2005).

${ }^{15}$ This question and how I form answers to it ought to be regarded in an ontologically neutral way; the question could easily be reformulated to reflect type-token relations (to be the same comic is to token the same type) or plate-process-print relations (to be the same comic is to be printed from the same plate).
} 
However, in the absence of further argument, we should take authorship itself to be more or less metaphysically neutral, e.g., absent further argument, one shouldn't conflate comic authorship with comic individuation. While determining the specifics of comic individuation is certainly an interesting project, it certainly isn't mine. That said, my view of comic authorship remains well-suited for employ in some further metaphysical view should one choose to do so (e.g., author essentialist view of works of certain sorts).

At this point, one might cry foul, claiming that I have yet to offer any insights into comic authorship or that I cannot provide any such insights given the strikingly uninformative account of what it is to be a comic heretofore employed. This clearly misses the point; the strength of my view is precisely that authorship doesn't vary according to work-descriptions (e.g., if we know exactly what it is to be an author, then our not knowing what it is to be an author of a comic just is our not knowing what it is to be a comic). Most importantly, authorship shouldn't be tested against theories of comics; rather, any theory of what it is to be a comic ought to be tested against authorship (at least as I have described it). If we assume comic to be an author-relevant work-description, then we must also assume that any theory of comics must entail a coherent account of comic authorship. Notice, however, that entailing a coherent account of comic authorship should not be viewed as a mark for a theory of comics; rather, entailing a coherent account of comic authorship should be seen as necessary condition on any theory of comics' prima facie viability. That is, if a theory of comics is such that no one even in principle could be directly responsible for the manner in which something satisfies the conditions for being a comic, then according to that theory, comics cannot even in principle have authors. To even seriously entertain such a claim requires such a radically revisionary notion of comic that we ought to regard any theory entailing that comics cannot even in principle have authors ipso facto unable to be even prima facie viable as a theory of comics. ${ }^{16}$

\section{ILLUSTRATING ROBUST COMIC AUTHORSHIP}

An account of comic authorship is only as robust as the theory of comics out of which it falls. So, for purely illustrative purposes, I adopt Scott McCloud's (1994) definition of comics. ${ }^{17}$

\footnotetext{
${ }^{16}$ I do think investigating comic authorship may well turn out to be broadly informative at least with respect to authorship for works of certain other sorts (namely film). Comics (i) intuitively have authors (i.e., comic is an author-relevant work-description), (ii) are often collectively produced but in a manner far less complex than that of film, and (iii) involve elements of other work-descriptions (visual and literary components). Furthermore, comic qua work-description is not obviously or traditionally considered an artform, and so perhaps less likely than other work-descriptions to be muddled by art-theoretic issues. For related issues in film, see (Gaut 1997; Livingston 1997; Sellors 2007; Meskin 2008).

${ }^{17}$ McCloud's I think is the most instructive in virtue of being one of the earliest and still best known definitions of comics as well as developed from an "insider's" point of view-McCloud is the author of the comic Zot! (1984).
} 
According to McCloud, comics are juxtaposed images in deliberate sequence intended to convey information and/or produce an aesthetic response in the reader. The principal constituent of comics are images; the images are juxtaposed with one another; this juxtaposition results from the images' position in the sequence; the sequencing itself gets determined according to the information such sequencing is intended to convey and/or the aesthetic response intended to be produced in the reader. So, while a particular comic must have images, what images are had depends upon the juxtaposition, which in turn depends on the sequencing, which in turn depends on what particular purpose the sequencing is intended to serve.

First, notice the above when combined with the progression and development of the techniques typically employed in comic production looks to ground contemporary comic conventions and practices. Contemporary comic practice isn't, compared to its Golden Age forbearer, more pluralistic with regard to comic authorship because of some new found, deep commitment to egalitarianism or labor rights. Colorists, inkers, and letterers are considered candidates for comic authorship largely because the techniques, technologies, and styles involved in coloring, inking, and lettering have evolved in such a way as to now offer substantial contributions both to content and the aesthetic reception. Moreover, this underpins why one might consider comics produced under the old, assembly-line, studio system of production to be, in a sense, "authorless" comics. Under this system, colorists, inkers, and letterers often weren't entirely aware of exactly what they were coloring, inking, and lettering (often even writers and pencillers had little to no contact with one another). As this changed, so too did attitudes regarding coloring, inking, and lettering, both professionally and in terms of how comics were received.

Consider again Batman: The Killing Joke. Higgins' coloring, like the coloring of many superhero comics from the 1980s and earlier, fails to be a constitutive component of the narrative. Coloring for much of the history of mass-art comics functions like background music; it makes the experience more pleasant but doesn't demand attention to its particulars (it need only be musical/colored within a broad range rather than be any particular music/color) — the same holds for the history of inking and lettering. So, one could plausibly contend that Higgins' coloring is such that Higgins fails to be an author for The Killing Joke (1988) (i.e., either that the coloring itself is not constitutive of The Killing Joke (1988) as a comic or that the intentions directing the production activities of coloring, of which Higgins is the source, failing to substantively figure even in part for whatever makes The Killing Joke (1988) a comic). Bolland's coloring, however, is nuanced and complex, complimenting and deepening both narrative and theme. So, perhaps Bolland's coloring (and Bolland's intentions directing his coloring) is such 
that Bolland qua colorist is an author for The Killing Joke (2008). Just as two people may share a destination but differ as to arrival method, I suppose that The Killing Joke (1988) and The Killing Joke (2008) share purpose $P$ but differ with respect to the elements employed to fulfill $P$. Moreover, imagine that The Killing Joke (1988) and (2008) are visually indistinguishable. We might nevertheless count Bolland but not Higgins as author qua colorist. In this case, Higgins would fail to be an author and Bolland would be an author who failed. ${ }^{18}$

While authorship is intention-dependent, presumably, in many cases, exactly whose intentions matter won't be clear. Often authorship of a comic gets attributed to that comic's creative director. For example, B.P.R.D. comics are created by Mike Mignola, and Watchmen was created by Alan Moore, though neither Mike Mignola nor Alan Moore contributed any artwork (Watchmen was illustrated by Dave Gibbons and colored by John Higgins). ${ }^{19}$ That comics can have a sole author that does not draw, ink, color, or letter isn't the problem. Determining when the creator is the author, an author (one among others), or not an author at all looks to be the problem. For example, Alan Moore is infamously known for being controlling-Moore not only creates the story, he also writes the script, which he then turns into a panel by panel breakdown, describing each panel, what objects it contains, where they are located, how they should look, and how that panel fits in with those before it and those after it. ${ }^{20}$ Recall that, at least according to McCloud's definition, being an author entails not just being responsible for a thing possessing images, image juxtaposition, and image sequencing but also being responsible for that thing's possession of those elements with respect to some purpose. Presumably, Alan Moore at least gets to be an author of Watchmen in virtue of determining the purpose those relevant features are supposed to serve, but what further distinctions can and must be made?

\section{COMIC AUTHORSHIP OF THE MCCLOUDIAN SORT}

Again, assuming Scott McCloud's (1994) definition of comics: ${ }^{21}$

A work $w$ is a comic if and only if $w$ possesses some $C\left[C_{w}\right]$ and some $P\left[P_{w}\right]$ such that $C_{w}$ is constituted largely with respect to $P_{w}$.

\footnotetext{
${ }^{18}$ For an in-depth analysis of failure in art, see (Mag Uidhir 2010).

${ }^{19}$ Actually, Mignola does the cover art for all of his comics. For the most part, however, the cover art is typically done by yet another party (one not involved with the comic's "interior"), and as such we can also legitimately ask whether the cover artist ought to count as an author.

${ }^{20}$ DC Comics is also notorious for this kind of control over its artists, while Marvel is known for being much freer. Marvel tells the artist that on page one, Wolverine walks into a room and spots the Hulk. DC tells the artist "Panel One: close up of Wolverine in the doorway, he is chomping a cigar looking twelve degrees to the left..."

${ }^{21}$ Note that I do not make claims about what it is to be a comic, what it is to be the author of a comic, or the particular merits or demerits of McCloud's definition-for that see (Meskin 2007; Hyman and Pratt 2005). My account of authorship merely shows what it is to be an author of a McCloudian comic, i.e., how to determine comic authorship given a McCloudian definition of comics.
} 
Being a comic isn't simply i) being a sequence of images and ii) being intended to fulfill some narrative or aesthetic purpose; rather, being a comic requires image sequencing in service to some narrative or aesthetic purpose. ${ }^{22}$ This must be reflected in what it is to be an author of a comic. So:

$A$ is an author of $w$ as a comic if and only if $A$ is directly responsible, at least in part, for $C_{w}$ being constituted with respect to $P_{w}$.

Comics with single authors are comics for which only one person is directly responsible for C's constitution with respect to $P$. Collectively authored comics must then be not just collectively produced comics but comics for which multiple people or agents are directly responsible for C's being constituted with respect $P$, each author bearing the same type of relation to the work and therefore to one another. The above framework for comic authorship allows us to ground the following crucial distinctions between singularly-authored collectively-produced comics (either an appropriation case or a commission case) and collectively-authored collectively-produced comics (either collaborative or non-collaborative). Of course, one needn't endorse McCloud's definition (or at least my reading of it) to make the above informative and productive distinctions. In fact, any prima facie viable theory of comics must entail an account of comic authorship able to coherently support the above distinctions, and any theory of comics out of which such distinctions cannot coherently emerge or emerge as neither productive nor informative ipso facto can itself be neither coherent nor informative and productive as a theory of comics.

Before I address collective authorship in comics (collaborative or non-collaborative), I must first discuss how best to characterize collectively produced but singularly authored works, namely as either appropriation cases or as commission cases.

\section{APPROPRIATION CASES}

Consider Dan Walsh's comic strip Garfield Minus Garfield. To create his work, Walsh selects certain Garfield comics (authored by Jim Davis), then removes the images of the character Garfield from those Garfield comics. ${ }^{23}$ To be a Garfield Minus Garfield comic is to have a Garfield

\footnotetext{
${ }^{22}$ Suppose an analogous account of poems. I take it that on such an account being a poem isn't simply i) being a verse composition in a natural language and ii) being intended to fulfill some narrative or aesthetic purpose; rather, I take that being a poem requires being a verse composition in service to some narrative or aesthetic purpose.

${ }^{23}$ In the Garfield comic, Garfield's owner Jon converses and regularly interacts in humorous ways with the titular cat. In Garfield Minus Garfield, there is no Garfield, only the character Jon. Garfield portrays Jon as a hapless but well-meaning character who attempts to control the antics of his mischievous cat, Garfield. In Garfield Minus Garfield, however, Jon is clearly both emotionally and mentally disturbed, terribly lonely and depressed, and perhaps even psychotic (e.g., he always appears to talk to himself, is prone to outbursts for no apparent reason, or simply stares at the wall). Garfield is typically light-hearted and
} 
comic as a proper part, but Garfield Minus Garfield comics are not Garfield comics. Although Walsh's work is a comic in virtue of his appropriation of Davis's comic, Davis, while directly responsible for Garfield being a comic, is in no way responsible for Garfield Minus Garfield being a comic. That is, Davis's intentions substantively figure only for Garfield being a comic, and do not figure at all for Garfield Minus Garfield being a comic. Garfield Minus Garfield may loosely be described as collectively produced in that Garfield Minus Garfield contains images that when considered alone were produced by someone other than Dan Walsh. ${ }^{24}$ Clearly though, Garfield Minus Garfield has nothing to do with Jim Davis's intentions and everything to do with Dan Walsh's intentions, so Garfield Minus Garfield has but one author.

\section{COMMISSION CASES}

Imagine that I want to make a comic with a certain narrative content. Rather than appropriating panel images from pre-existing Garfield comics, I instead hire Jim Davis to create some images for me. I send him a set of detailed instructions for each image but deliberately do so in such a way that he never comes to believe that these images bear (or are intended to bear) any relation to one another. Davis doesn't think he is creating panel images, only discrete, stand-alone images. The juxtaposition of these drawings according to a sequence, let alone with respect to a particular purpose, simply doesn't figure for Davis. So, Davis's intentions cannot substantively figure in any relevant relations the images bear to one another. Even though every panel in the comic features an image, for which, considered alone, Jim Davis is the sole author, I am nevertheless the sole author of the comic featuring those images. My intentions and my intentions alone substantively figure in the work possessing the relevant comic properties, and images, considered discretely, aren't relevant for being a comic—images are relevant for being a comic only when considered relationally (e.g., image paneling). That the work possesses these images and how these images, in virtue of their sequencing, serve the narrative and thematic content has absolutely nothing to do with Jim Davis's intentions and everything to do with mine. The comic may have been collectively produced but the comic isn't collectively authored; I am the sole author of the comic.

Consider the graphic novel The Filth (2004), for which the salient production credits are as follows: Grant Morrison (writer), Chris Weston (penciller), Gary Erskine (inker), Matt

humorous; Garfield Minus Garfield is typically poignantly sad and darkly humorous. The strip Arbuckle does much the same; it leaves Garfield in the strip but removes Garfield's thought bubbles so as to represent Jon's experience of non-verbally "communicating" with his cat. Also Garfield Radomizer randomly selects and juxtaposes three panels from Garfield strips so as to create a new three-paneled comic.

${ }^{24}$ While Davis still writes and develops stories for Garfield, his assistants carry out most of the comic's physical production (drawing according to Davis's famous style). 
Hollingsworth (colorist), and Clem Robins (letterer). ${ }^{25}$ Most people's intuitions about comic authorship point toward the writer and penciller (though often not to the same degree), i.e., if anyone is an author of The Filth, then it must be Morrison if not also Weston. Other contributory roles fair considerably less well, i.e., some view inkers as glorified tracers, colorists as glorified computer operators, and letterers as, well, unglorified letterers. We shouldn't simply dismiss letterers out of hand as potential comic authors; rather, being so dismissed should result from systematically showing that no agent can be a comic author merely qua letterer. Similarly, we shouldn't just assume, as many of us do implicitly if not explicitly, that writers have the greatest claim to comic authorship; rather, we should see if these intuitions could be supported in terms of the nature of the relation (symmetric or asymmetric) between authors in cases of collective authorship.

\section{Collaborative CASES}

Suppose that I hire Jim Davis to illustrate the work. I have written the script and have broken that script down into meticulously detailed panel-descriptions, which I then provide as instructions to Davis. Notice that in this case Davis draws the image in the panel-description as just that, a paneled image. That is, in this case, Davis is not only aware of the intended narrative and thematic content but also aware of how the images described in the detailed panel descriptions relate to that narrative and thematic content in virtue of how those images relate to the other images described in other panel-descriptions. Davis then draws the images with this in mind. So, the activities from which the images substantively result are not merely directed by the intention that they conform to the detailed sketches I provided (merely following instructions) but by the intention that they look a certain way in virtue of how looking that way relates to the narrative and thematic content-how looking a certain way relates to other images, their juxtaposition and sequencing, and how this relates to the narrative and thematic content. Notice that if Davis fails to be aware of this or fails to have this inform the intentions directing his activities, then this collapses into a commission case. ${ }^{26}$ That the work possesses these images and how these images relate to the narrative and thematic content, in this case, has everything to do with Davis's intentions. Therefore, the comic has two authors. Of course, we might further claim that since my intentions govern the conditions under which Davis's intentions are allowed to figure, though Davis is an author, I am the primary author-Davis's

\footnotetext{
${ }^{25}$ Often only the color studio (e.g., Hi-Fi) rather than an actual person will be listed as the colorist. While one could make the case that studios count as a collective agents and as such are prima facie candidates for comic authors (at least inasmuch as actual, single-agented colorists).

${ }^{26}$ Davis strictly following my meticulously detailed instructions doesn't entail that Davis is merely following my meticulously detailed instructions.
} 
intentions substantively figure only if my intentions substantively figure. After all, not all collaborations must be equal. For this to be a truly equal collaboration requires the way in which I am directly responsible for the work being a comic to inform/affect and be informed/affected by the way in which Davis is directly responsible for the work being a comic.

\section{Non-COllaborative CASES}

McCloud's definition appears at least prima facie to exclude non-collaborative collective authorship. ${ }^{27}$ The features required for a work's being a comic (image, juxtaposition, sequence, purpose) depend on one another; no feature counts as constitutive non-relationally, independent of the others. $A^{\prime}$ s intentions may figure substantively in $w$ possessing a particular discrete image, but this doesn't entail that $A^{\prime}$ 's intentions substantively figure in $w$ as $a$ comic-discrete images aren't constitutive components of McCloudian comics. Crudely put, $A$ and $B$ cannot simply divvy up comic production (e.g., $A$ produces the image sequencing and $B$ produces the narrative content), complete their assigned roles, and have a comic result. In fact, such cases, when coherent, appear to be commission or appropriation cases rather than collective authorship cases (i.e., a comic, of which $A$ is not an author, that nevertheless has components produced by $A$ that are constitutive of the comic only as a substantive result of $B^{\prime}$ s intentions). Of course, to object to the rejection of non-collaboratively collectively-authored comics just is to object to McCloud's definition of comics (or at least to my reading of McCloud's definition of comics). The important point is that, at least as I have described it, authorship is easy, so comic authorship can only be as complicated as comic.

\section{FINAL THOUGHTS}

Using the preceding analysis, perhaps the history of mass-market comics can instructively be seen in terms of moving from commission cases to collaborative cases. When writers or artists get employed only in virtue of being able to write stories or produce images in a standard (conventional) style, commission cases should be common. When writing and artistry begin to become more nuanced and complex, as in contemporary comics, we begin to see more collaborative cases. Mechanical skill or stock storytelling isn't enough anymore. Writers and

\footnotetext{
${ }^{27}$ Assume that [F iff $f_{1}$ and $f_{2}$ ] and that both $f_{1}$ and $f_{2}$ can be satisfied independently from the other, and let $A^{\prime}$ s production contribution $(A P)$ satisfy $f_{1}$ and $B^{\prime}$ s production contribution $(B P)$ satisfy $f_{2}$. From this it follows that $w$ as an $F$ is a case of non-collaborative collective-authorship just in case: (i) only $A P$ and $B P$ are constitutive of $w$ as an $F$ (Collective Production), (ii) only $A$ 's intentions substantively figure in $A P$ being constitutive of $w$ as an $F$, (iii) only $B^{\prime}$ s intentions substantively figure in $B P$ being constitutive of $w$ as an $F$, (iv) it is not the case that [ $A P$ if or only if $B P$ ], and (v) $A$ is an author of $w$ as an $F$ and $B$ is an author of $w$ as an F (Non-Collaborative Collective Authorship).
} 
creators want artists who can understand the complexities and nuances of their scripts or creative visions, and create images in virtue of that understanding (e.g., Moore and Gibbons on Watchmen). Likewise, artists seek writers or creators with nuanced and complex scripts or projects that they can make more complex or nuanced in virtue of their artistry (e.g., Tim Sale's illustration of Jeph Loeb's story in Batman: The Long Halloween). Of course, the best sort of collaboration results when the authors creatively compliment each other (e.g., Grant Morrison's story and Dave McKean's paintings in Arkham Asylum or Frank Miller's frantic line art and Lynn Varley's wild, garish coloring in The Dark Knight Strikes Again). Note that being a writer of a comic doesn't entail being an author of that comic, or if an author, being the "primary" author. Just as images can be appropriated and artists commissioned, so too for scripts, stories, and writers.

Finally, whether or not one finds McCloud's definition of comics persuasive, questions of comic authorship, collective or otherwise, can be properly answered only by first specifying the work-description comic. Determining the work-description comic then allows for determining whom, if anyone, is directly responsible, at least in part, for the work being under that description. Subsequently, the presence of any (or at least a preponderance of any) nonempirical difficulties in determining comic authorship suggests that the source of the difficulty firmly rests with that operative theory of comics, revealing either that the work-description comic itself is in principle resistant to authorship or that the account of comics under consideration is itself unworkable. For if it turns out that comic is an elusive or fractious workdescription, then comics are ipso facto works for which authorship is elusive or fractious. ${ }^{28}$ Most importantly, comic authorship is no queerer a thing than authorship of any other sort. The sort comic, however, may well be a queer thing indeed.

\footnotetext{
${ }^{28}$ Should comic be a hybrid work-description (Meskin 2009), comic authorship must also be hybrid.
} 


\section{REFERENCES}

Ault, D. (2004). Preludium: Crumb, Barks, and Noomin: Re-Considering the Aesthetics of Underground Comics. ImageTexT: Interdisciplinary Comics Studies. 29 July 2010. http:/ / www.english.ufl.edu/imagetext/archives/v1_2/intro.shtml.

Gaut, B. (1997). Film authorship and collaboration. In R. Allen \& M. Smith (Eds.), Film theory and philosophy. Oxford University Press.

Hyman, G. \& Pratt, H. (2005). What are comics? In D. Goldblatt \& L. Brown (Eds.), A reader in the philosophy of the arts. Upper Saddle River, NJ: Pearson Education, Inc.

Irving, C. (2010). Talking Comics with Scott McCloud. NYC Graphic. March 1 ${ }^{\text {st }}, 2010$.

http: / / www.nycgraphicnovelists.com / 2010/03/talking-comics-with-scott-mccloud.html

Levinson, J. (1990). Music, art, and metaphysics. Ithaca: Cornell University Press.

Livingston, P. (1997). Cinematic authorship. In R. Allen \& M. Smith (Eds.), Film theory and philosophy. Oxford University Press.

Mag Uidhir, C. (2010). Failed-art and failed art-theory. Australasian Journal of Philosophy 88(3): 381-400.

Mag Uidhir, C. (2011). Minimal authorship (of sorts). Philosophical Studies (forthcoming).

McCloud, S. (1994). Understanding comics: The invisible art. Harper Paperbacks.

Meskin, A. (2005). Defining comics? Journal of Aesthetics and Art Criticism, 65: 369-379.

Meskin, A. (2008). Authorship. In P. Livingston \& C. Plantinga (Eds.), Routledge companion to philosophy and film. Routledge.

Meskin, A. (2009). Comics as literature? British Journal of Aesthetics 49(3): 219-239.

Rohrbaugh, G. (2005). I could have done that. British Journal of Aesthetics, 45(3): 209-228.

Sellors, C.P. (2007). Collective authorship in film. Journal of Aesthetics and Art Criticism, 65: 263271. 